\title{
Study on infant feeding practice among children up to 6 months in an urban slum of Bhopal
}

\author{
Sarkar R. ${ }^{1}$, Kawanpure $\mathrm{H}^{2 *}$ \\ DOI: https://doi.org/10.17511/ijphr.2021.i03.02 \\ ${ }^{1}$ Ria Sarkar, Post Graduate Resident, Department of Community Medicine, People's College of Medical Sciences \& Research Centre, Bhopal, \\ Madhya Pradesh, India. \\ 2* Harshal Kawanpure, Associate Professor, Department of Community Medicine, People's College of Medical Sciences \& Research Centre, \\ Bhopal, Madhya Pradesh, India.
}

Introduction: High morbidity and mortality among the under 5 children are highly prevalent in India. Appropriate child feeding practices in the initial six months of age act as a preventive intervention against childhood morbidity and mortality. Methods: A questionnaire-based crosssectional study was conducted in an urban slum to study various feeding practices prevalent among children up to 6 months of age. Also associated socio-demographic factors were studied. SPSS software version 25 was used to analyze the results. Results: The study included 55 children up to 6 months of age. Out of these $76.4 \%$ were exclusively breastfed. Among $45.5 \%$, breastfeeding was within $1^{\text {st }}$ hour of the birth. $56.4 \%$ have received pre-lacteal feeds, while $72.72 \%$ received colostrum. The educational status of the mother and place of delivery were major determinants of appropriate infant feeding practices. Conclusion: Most mothers are practising exclusive breastfeeding. Colostrum was fed to most of the children. Animal milk was given in cases where initiation of breastfeeding was delayed.

Keywords: Appropriate child feeding practices, Colostrum feeding, Pre-lacteal feed, Exclusive breastfeeding, Mother's education

\section{Corresponding Author}

Harshal Kawanpure, Associate Professor, Department of Community Medicine, People's College of Medical Sciences \& Research Centre, Bhopal, Madhya Pradesh, India.

Email: hkawanpure@gmail.com

\section{How to Cite this Article}

Sarkar R, Kawanpure H. Study on infant feeding practice among children up to 6 months in an urban slum of Bhopal. Public Health Rev Int J Public Health Res. $2021 ; 8(3): 39-44$.

Available From

https://publichealth.medresearch.in/index.php/ijphr/ article/view/162
To Browse

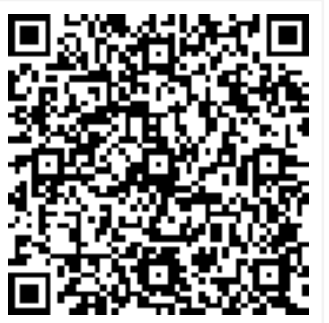

Manuscript Received 2021-05-03

Conflict of Interest No
Review Round 1 2021-05-13

Funding

Review Round 2
$2021-05-23$
Ethical Approval
Yes

Review Round 2

Yes

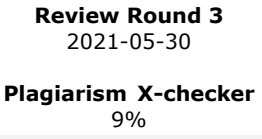

Accepted 2021-05-10

Note 


\section{Introduction}

India still accounts for the highest prevalence of child under-nutrition in the world. This further contributes to high morbidity and mortality, especially among the under 5 children [1]. India State-Level Disease Burden Initiative Malnutrition Collaborators states that undernutrition is the leading risk factor for mortality among children under 5 years of age, in 2017. It stated that child stunting in India in 2017 was 39.3\%; while the prevalence of child wasting and child underweight was $15.7 \%$ and $32.7 \%$ respectively. The prevalence of overweight among children aged 2-4 years was $11.5 \%$ [2]. Appropriate feeding practices are a basic fundamental need for the survival, growth, and development of infants and young children. Studies suggest that optimal feeding of a young child, increases his potential to survive by six-folds. Hence, it is estimated that, one can prevent over 800,000 under-five deaths (almost 13 per cent of all deaths) in developing countries, just by improving the child feeding practices [3]. Several studies have suggested that exclusive breastfeeding in the initial six months of life, act as preventive interventions in the prevention of several diseases. As per NFHS-4, data suggests that in urban areas of Madhya Pradesh, only $54.2 \%$ of children under age 6 months are exclusively breastfed [4]. The objective is to study various feeding practices prevalent among children up to 6 months of age in an urban slum of Bhopal and to access various sociodemographic factors affecting exclusive breastfeeding and appropriate breastfeeding practices.

\section{Methods}

The study was conducted in the Satnami Nagar, Indrapuri, an urban slum area of Bhopal, Madhya Pradesh. This community based cross-sectional analytical study was conducted in children up to six months of age, from October 2018 to February 2019. Line-listings of all the children up to 6 months of age, were obtained from the local Anganwadi centre. A universal sample was taken. All the children, who were born singleton and full-term (greater than 37 weeks), and whose mothers were willing to participate in the study, were included in the study. A child born with any physical or congenital abnormality and those suffering from any prolonged or contagious illness, were excluded. Prior informed consent was obtained from the mothers.
The mothers were interviewed with a pre-designed questionnaire, based on the recently published module titled "Indicators for assessing infant and young child feeding (IYCF) practices," by World Health Organisation, which was adapted to suit our study [5]. A fair idea about the feeding practice among the babies was assessed by asking the mother about the frequency and type of feed and their amounts given during the previous day (based on recall method). No ethical issues involved as the study was a cross-sectional study and only those participants were included who gave prior consent. The results were analysed using SPSS software version 25 .

\section{Result}

63 subjects were identified of which 59 gave consent to participate in the study. Based on inclusion and exclusion criteria, 55 babies were included in the study. Table 1 depicts the demographic profile of study subjects. The mean age of children included in the study was 3.94 months. There were $28(50.9 \%)$ female and 27 $(49.1 \%)$ male children. The minimum birth weight of the child observed was $2.5 \mathrm{Kgs}$ and maximum was $3.9 \mathrm{Kgs}$, mean birth weight recorded was 2.75 Kgs. Among the mothers, $28(50.90 \%)$ belong to the age group 18 to 24 years, followed by 21 $(38.18 \%) 25$ to 30 years, and $3(5.45 \%)$ each in the age groups 31 to 35 years and more than 35 years, as shown in table 2 .

\section{Table-1: Demographic profile of study} subjects.

\begin{tabular}{|l|l|l|l|l|l|}
\hline \multicolumn{1}{|c|}{ Variable } & N & Minimum & Maximum & Mean & Std. Deviation \\
\hline $\begin{array}{l}\text { Age of the baby (in } \\
\text { months) }\end{array}$ & 5 & 1 & 6 & 3.94 & 1.66 \\
\hline $\begin{array}{l}\text { Age of the mother (in } \\
\text { years) }\end{array}$ & 5 & 20 & 37 & 25.42 & 4.1 \\
\hline Birth Weight (in kgs) & 5 & 2.5 & 3.2 & 2.75 & 0.26 \\
\hline
\end{tabular}

\section{Exclusive breastfeeding}

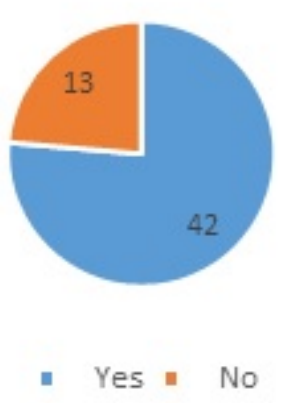




\section{Figure-1: Children receiving Exclusive Breastfeeding}

Table-2: The age group of mothers.

\begin{tabular}{|l|l|l|}
\hline Mother's Age group (Years) & Frequency(N=55) & Percentage(\%) \\
\hline $18-24$ & 28 & 50.90 \\
\hline $25-30$ & 21 & 38.18 \\
\hline $31-35$ & 3 & 5.45 \\
\hline$>35$ & 3 & 5.45 \\
\hline
\end{tabular}

\section{Colostrum}

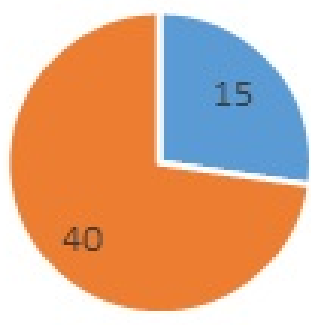

- NO $\square$ YES

Figure-2: Children receiving Colostrum

\section{Time initiation of Breastfeeding}

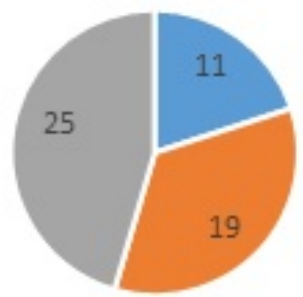

- $>24$ hour $\quad 1-24$ Hour $\|<1$ hour

Figure-3: Time initiation of Breastfeeding

\section{Pre-lacteal feeds}

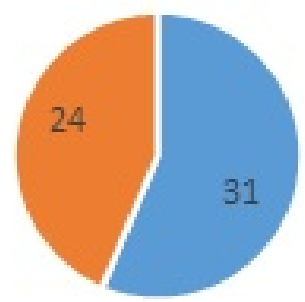

- YES $=\mathrm{NO}$

\section{Figure-4: Children receiving Pre-lacteal feeds}

Table 3 depicts that $76.4 \%$ of mothers are aware of exclusively breastfeeding and are practising it. More than half of the babies, $31(56.4 \%)$ have received pre-lacteal feeds in form of milk from animal sources, due to delay in initiation of breastfeeding because of several reasons like, lack of sensitization, caesarean section, non-production of milk, etc. Although, it was found that most of the mothers, $25(45.5 \%)$, initiated breastfeeding within 1 st-hour post-delivery. In $11(20 \%)$ babies, breastfeeding was initiated after 24 hours of birth. $40(72.7 \%)$ mothers know about colostrum and its advantages and had fed colostrum to their babies. The majority of the mother, i.e. $37(67.3 \%)$, are well versed with appropriate breastfeeding techniques and are optimally breastfeeding their babies. Most of the babies, 42 (76.4\%) are being breastfed appropriately in terms of feeding technique, adequacy and frequency.

Table-3: Infant feeding practice among children up to 6 months

\begin{tabular}{|l|l|l|}
\hline \multicolumn{1}{|c|}{ Variables } & Frequency $(\mathbf{n = 5 5 )}$ & Percentage (\%) \\
\hline Colostrum feeding & \multicolumn{2}{l|}{} \\
\hline Yes & 40 & 72.7 \\
\hline No & 15 & 27.3 \\
\hline Pre-lacteal feeding & 56.4 \\
\hline Yes & 31 & 43.6 \\
\hline No & 24 & \multicolumn{2}{|l|}{} \\
\hline Time initiation of breastfeeding & 20.0 \\
\hline$>24$ hour & 11 & 34.5 \\
\hline $1-24$ Hour & 19 & 45.5 \\
\hline$<1$ hour & 25 & 76.4 \\
\hline Exclusive breastfeeding & 23.6 \\
\hline Yes & 42 & \\
\hline No & 13 & \\
\hline
\end{tabular}

In table $4,72.72 \%$ of the housewives and $90.9 \%$ of working women were well versed with the benefits of appropriate breastfeeding and were practising it. $32(78.04 \%)$ mothers, who underwent institutional delivery, adhered to appropriate breastfeeding compared to 10 (71.4\%)of mothers, who delivered at home. It is also indicated that appropriate breastfeeding practices are most common in third Generation families 11 (78.57\%), followed by extended families 23 (76.66) and least in nuclear families 8 (72.72\%). Compared to illiterate mothers, educated mothers had better sensitised to the advantages of appropriate breastfeeding. On one hand, appropriate feeding was more common in mothers with primary and secondary education, 18 
$(85.71 \%)$ and $16(84.2 \%)$, on the other hand, 6 $(54.54 \%)$ out of 11 illiterate mothers were inappropriate feeding their children.

\section{Table-4: Factors associated with infant feeding} practices

\begin{tabular}{|c|c|c|c|}
\hline \multirow[t]{2}{*}{ Variables } & \multicolumn{3}{|c|}{ Appropriate Breastfeeding practices } \\
\hline & Yes & Percentage (\%) & No Percentage (\%) \\
\hline \multicolumn{4}{|l|}{ Occupation } \\
\hline Housewife & 32 & 72.72 & \begin{tabular}{|l|l|}
12 & 27.27
\end{tabular} \\
\hline Working women & 10 & 90.9 & \begin{tabular}{l|l}
1 & 9.09
\end{tabular} \\
\hline \multicolumn{4}{|l|}{ Place of delivery } \\
\hline Home & 10 & 71.4 & \begin{tabular}{|l|l}
4 & 28.57
\end{tabular} \\
\hline Health institution & 32 & 78.04 & \begin{tabular}{l|l}
9 & 21.95 \\
\end{tabular} \\
\hline \multicolumn{4}{|l|}{ Type of Family } \\
\hline Nuclear & 8 & 72.72 & \begin{tabular}{|l|l|}
3 & 27.27 \\
\end{tabular} \\
\hline Extended & 23 & 76.66 & $7 \quad 23.33$ \\
\hline Third Generation & 11 & 78.57 & $3 \quad 21.42$ \\
\hline \multicolumn{4}{|l|}{ Mother's Education } \\
\hline Illiterate & 5 & 45.45 & $6 \quad 54.54$ \\
\hline Primary & 18 & 85.71 & $3 \quad 14.28$ \\
\hline Secondary & 16 & 84.2 & \begin{tabular}{|l|l}
3 & 18.78
\end{tabular} \\
\hline High school and above & 3 & 75 & $1 \mid 25$ \\
\hline
\end{tabular}

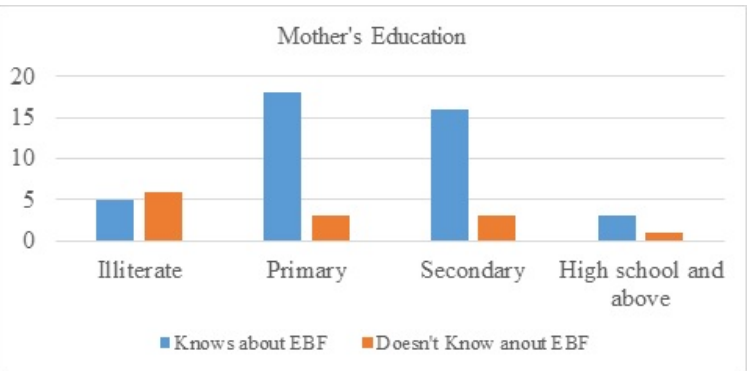

Bar chart 1. Trends between mother's education and her knowledge of EBF

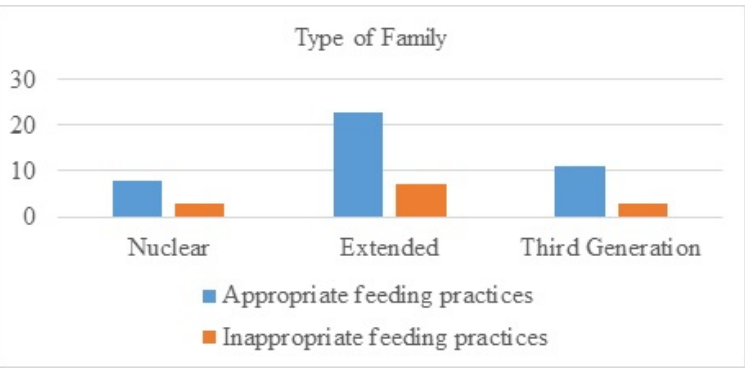

\section{Bar chart 2. Trends between feeding practices and type of family}

Appropriate feeding practices as per WHO norms are highly dependent on the educational status of the mother. Bar chart 1 shows the trends between a mother's education and her knowledge of EBF.
It is evident that mothers who are educated, have a better understanding of the benefits of exclusive breastfeeding and are practising it. Bar chart 2 shows that proper feeding practices are more prevalent in joint families and extended families irrespective of their social status.

\section{Discussion}

A noticeable improvement of $76.4 \%$ was noted in exclusive breastfeeding of children as compared to $54.2 \%$ as suggested by NFHS-4. A similar EBF prevalence of $79.2 \%$ was observed in the southern states of India which is considered highest as per the findings of Felix Akpojene Ogbo, et al [6]. This was found to be much better compared to the Kol tribal community of Madhya Pradesh, where only $20.3 \%$ of infants are being exclusively breastfed [7]. It was observed that more than half of the babies, 31 (56.4\%) have received pre-lacteal feeds. This was significantly higher than the findings of Das A, et al, where $26.17 \%$ received some form of food instead of breast milk [8]. In this study, milk from animal sources was the most frequently identified pre-lacteal feed. This practice was not associated with custom, but with delay in initiation of breastfeeding.

Contrary to this, in the study conducted by Madhu $K$, et al, sugar water $(13 \%)$, honey $(6 \%)$ and ghee (3\%) were common pre lacteal feeds identified [9]. Benakappa DG, et al, also found a large number of babies being fed with Sugar water (53.07\%) and castor oil (9.72\%) [10]. Several studies suggest that timely initiation of breastfeeding is associated with better adherence to EBF and hence improved chances of neonatal survival [11]. In this study, we found, $45.5 \%$ of mothers initiate breastfeeding within 1st hour. This was exactly in line with the findings of Sultania $P$, et al., where, $45 \%$ of mothers started breastfeeding within one hour after the birth of the baby [12]. This also strengthens the UNICEF data which suggests that $41 \%$ of mothers initiate breastfeeding within one hour of birth [3]. A positive observation in this study was that now a higher percentage, i.e. $72.7 \%$ of mothers are giving colostrum to their babies. This was much improved than the findings of previous studies where only $56 \%$ of the babies were fed with colostrum [13].

Similar to the findings of Dasgupta $A$, it is observed that mothers with better educational status have better adherence to appropriate breastfeeding practices [14]. 
Moestue $\mathrm{H}_{\text {., }}$ also mentioned in his study that a child's better nutritional status is associated with parents' and grandparents' education levels [15]. In the current study, appropriate breastfeeding was prevalent in both institutional well as home-based deliveries. This was in contrast to the findings of Liaquathali $F$, where, mothers who delivered by caesarean section, the prevalence of appropriate Infant and young children feeding practices were higher [16]. Kogade $P$, stated in his study that family size and type major determinants of IYCF practices in rural India [17]. This was further strengthened by our study, where, it was remarkable that appropriate feeding practices are more prevalent in joint families and extended families irrespective of their social status.

\section{Conclusion}

It is commendable to note that breastfeeding is universally accepted as an essential component of child survival, and most of the mothers are breastfeeding their newborns. By large, it is noticed that the majority of mothers are practising exclusive breastfeeding. Most of the children have received colostrum. A large scope of improvement in the timely initiation of breastfeeding is seen in this study. A mother's adherence to appropriate feeding practice is greatly determined by her education status, type of family, and the place where she delivered the baby. Even the mothers with basic primary education and above, have a better insight into appropriate breastfeeding. Better adherence to appropriate breastfeeding practice in joint and extended families are suggestive of better childcare and child-rearing guidance provided to the mothers. Also it is noted that institutional deliveries provide an opportunity to sensitize the mothers for timely initiation of breastfeeding. Also it gives a chance to improve the breastfeeding technique among the new mothers so that babies are not fed with animal milk. Strengthening healthcare facilities as well as communities to provide guidance and support to the mothers is a key to further improve the IYCF practices. This can be done by sensitizing the mothers about colostrum and breastfeeding, right from their first ANC visit. There is an urgent need to improve the IYCF practice in the identified community. This can be achieved by conducting outreach programs with the help of the ASHA and Aanganwadi workers. Periodic training of the grassroot level workers will help in sustaining the improvement in IYCF practice and reducing the burden of infant morbidity and mortality.

\section{Reference}

01. India State-Level Disease Burden Initiative Malnutrition Collaborators. The burden of child and maternal malnutrition and trends in its indicators in the states of India- the Global Burden of Disease Study 1990-2017. Lancet Child Adolesc Health. 2019 Dec;3(12)855-870. doi: 10.1016/S23524642(19)30273-1 [Crossref][PubMed][Google Scholar]

02. India State-Level Disease Burden Initiative Child Mortality Collaborators. Subnational mapping of under-5 and neonatal mortality trends in India- the Global Burden of Disease Study 2000-17. Lancet. 2020 May 23;395(10237)1640-1658. doi: 10.1016/S0140-6736(20)30471-2 [Crossref] [PubMed][Google Scholar]

03. UNICEF. Nutrition- Malnutrition. [Cited 29 Sep, 2018]. Available at: [Article] [Crossref][PubMed] [Google Scholar]

04. International Institute for Population Sciences. National Family Health Survey-4, State fact sheet Madhya Pradesh, 2015 -16- India. Mumbai-IIPS. 2016. [Cited on 2018 December 21]. Retrieved from: [Article][Crossref][PubMed][Google Scholar]

05. World Health Organization. Indicators for assessing infant and young child feeding practicespart 1- definitions- conclusions of a consensus meeting held 6-8 November 2007 in Washington DC, USA. World Health Organization. 2008. [Crossref][PubMed][Google Scholar]

06. Ogbo FA, Dhami MV, Awosemo AO, Olusanya BO, Olusanya J, Osuagwu UL, et al. Regional prevalence and determinants of exclusive breastfeeding in India. Int Breastfeed J. 2019 May 16;14;20. doi: 10.1186/s13006-019-0214-0 [Crossref][PubMed][Google Scholar]

07. Tiwari B, Rao V, Mishra D, Thakur C S S. Infantfeeding practices among Kol tribal community of Madhya Pradesh. Indian Journal of Community Medicine. 2007;32(3)228-228. [Crossref][PubMed] [Google Scholar]

08. Das A, Mala G S, Singh R S, Majumdar A, Chatterjee $R$, Chaudhuri I, et al. Prelacteal feeding practice and maintenance of exclusive breast feeding in Bihar, India-identifying key demographic sections for childhood nutrition interventions- a cross-sectional study. Gates open research. 2019;3. [Crossref][PubMed][Google Scholar] 
09. Madhu K, Chowdary S, Masthi R. Breast feeding practices and newborn care in rural areas- a descriptive cross-sectional study. Indian J Community Med. 2009 Jul;34(3)243-6. doi: 10.4103/0970-0218.55292 [Crossref][PubMed] [Google Scholar]

10. Benakappa DG, Raju M, Shivananda, Benakappa AD. Breast-feeding practices in rural Karnataka (India) with special reference to lactation failure. Acta Paediatr Jpn. 1989 Aug;31(4)391-8. doi: 10.1111/j.1442-200x.1989.tb 01323.x [Crossref] [PubMed][Google Scholar]

11. Phukan D, Ranjan M, Dwivedi LK. Impact of timing of breastfeeding initiation on neonatal mortality in India. Int Breastfeed J. 2018 Jul 3;13;27. doi: 10.1186/s13006-018-0162-0 [Crossref][PubMed][Google Scholar]

12. Sultania $P$, Agrawal NR, Rani A, Dharel $D$, Charles R, Dudani R. Breastfeeding Knowledge and Behavior Among Women Visiting a Tertiary Care Center in India- A Cross-Sectional Survey. Ann Glob Health. 2019 May 3;85(1)64. doi: 10.5334/aogh.2093 [Crossref][PubMed][Google Scholar]

13. Ekambaram, Maheswari, Ballambattu Bhat, and Mohamed Asif Padiyath Ahamed. "Knowledge, attitude and practice of breastfeeding among postnatal mothers". Current Pediatric Research. 14;2(2010)119-124. [Crossref][PubMed][Google Scholar]
14. Dasgupta A, Naiya S, Ray S, Ghosal A, Pravakar $R$, Ram P. Assessment of infant and young child feeding practices among the mothers in a slum area of Kolkata- A cross-sectional study. Int J Biol Med Res. 2014;5(1)3855-3861. [Crossref][PubMed] [Google Scholar]

15. Moestue $\mathrm{H}$, Huttly $\mathrm{S}$. Adult education and child nutrition- the role of family and community. J Epidemiol Community Health. 2008 Feb;62(2)1539. doi: 10.1136/jech.2006.058578 [Crossref] [PubMed][Google Scholar]

16. Liaquathali F, Maruthupandian J, Govindasamy R. An assessment of age-appropriate infant and young child feeding practices among children in Kancheepuram district, Tamil Nadu, India. J Family Med Prim Care. 2020 Sep 30;9(9)4692-4698. doi: 10.4103/jfmpc.jfmpc_668_20 [Crossref][PubMed] [Google Scholar]

17. Kogade P, Gaidhane A, Choudhari S, Khatib M N, Kawalkar $U$, et al. Socio-cultural determinants of infant and young child feeding practices in rural India. Medical Science. 2019;23(100)1015-22. [Crossref][PubMed][Google Scholar] 